\title{
Past Achievements and Future Possiblities of Systemic-Functional Discourse/Text Analysis: In Memory of M. A. K. Halliday
}

\author{
Hengxing He \\ School of Foreign Studies, South China Normal University, Guangzhou, P.R. China
}

Email address:

hehengxing@m.scnu.edu.cn

To cite this article:

Hengxing He. Past Achievements and Future Possiblities of Systemic-Functional Discourse/Text Analysis: In Memory of M. A. K. Halliday. International Journal of Language and Linguistics. Vol. 7, No. 1, 2019, pp. 32-41. doi: 10.11648/j.ij11.20190701.15

Received: December 27, 2018; Accepted: January 21, 2019; Published: February 9, 2019

\begin{abstract}
M. A. K. Halliday passed away from us, but his linguistic influence is and will always be with linguistic academia, which is realized in the research on Systemic-Functional Discourse/Text Analysis (SFDA). This paper gives an overview of SFDA studies, and summarizes eight major contributions of SFDA, including construal of world famous discourse/text analysis (DA) theories, emergence of the "Golden Delta" of research, numerous publications, development of different analytic models, etc. And it argues that its future research orientations may include macro planning, micro deepening, theoretical exploration, practical standardization, and popularization and promotion. The conclusion is that there is a great potential for the development of SFDA.
\end{abstract}

Keywords: Discourse Analysis, Text Analysis, Systemic-Functional Discourse/Text Analysis

\section{Introduction}

"His life has passed but the amazing treasure of his intellect will thrive in all those touched by his work for generations to come." That is the last word of M. A. K. Halliday's obituary by Univerisity of Sydney (https://sydney.edu.au/news-opinion/news/2018/04/19/valeemeritus-professor-michael-halliday.html). Three year ago, the author of this paper published a Chinese article entitled

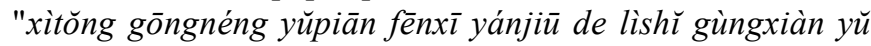
wèilái fāzhăn fāngxiàng" (Research of Systemic-Functional Discourse/Text Analysis (SFDA): Historical Contributions and Future Orientations) in the Chinese journal Foreign Language and Literature Research [33] in honour of this great linguist's ninetieth birthday. Now in memory of this very gracious founder of Systemic-Functional Linguistics (SFL), he suddenly had the impetus to better praise and spread Halliday's contributions to the linguistic academia around the globe when he felt honoured to receive an invitation from the editorial board of International Journal of Language and Linguistics to submit the English translation version of his Chinese article of this with updates to its journal. Now he has done it, and this paper is similar to the above-mentioned Chinese article of his in both topic and contents with a few updates and expansions as well as his gratitude to the Chinese journal Foreign Language and Literature Research and its editors, and Prof. Guowen Huang and Prof. Yong Wang for their kind help.

According to the website www.isfla.org, Halliday has contributed over 205 works (172 single-authored, 33 co-authored, based on Halliday's bibliography collated by Mick O'Donnell), and his linguistic influence is worldwide. Any topic relevant to him or his works or theory is of academic interest to the world, especially to the circle of SFL. And this echoes the word at the beginning of this paper, which will help display the amazing treasure of his intellect, works and influence from a perspective.

\section{Literature Review}

Discourse/text analysis (DA) has long been one of the significant research areas in linguistics. This can partly reflected in its journal publications. For example, by searching the key words of 'discourse analysis' and 'text analysis' respectively in the article titles at Web of Science website, we find 3, 237 (publication years ranging from 1971 to 2018) and 
2, 056 (publication years ranging from 1951 to 2018) results respectively.

SFDA research began as early as the 1950 s along with Halliday's Ph.D. Thesis submitted to Cambridge University entitled The Language of the Chinese Secret History of the Mongols where he mainly focused on the analysis of the Chinese grammar of the composite text in question [11: 1] on which he later developed into what is now called Systemic-Functional Grammar (SFG). Since then, sixty-three years has passed. Halliday and his followers have made great contributions to this research both in theory (e.g., Fawcett [4]; Martin \& White [65]) and practice (e.g., Fryer [7]; García et al. [8]) under the general background or support of SFL/SFG. One of the most significant realizations include Halliday's classic books such as Cohesion in English (co-authored with R. Hasan) [28], Language as Social Semiotic: The Social Interpretation of Language and Meaning [12], and An Introduction to Functional Grammar (1st ed., 2nd ed.) (IFG1 [14]; IFG2 [18]), and the eleven volumes of Collected Works of M. A. K. Halliday edited by Jonathan Webster and published from 2002 to 2013 [35,58]. Most worthy of mention is the second and eleventh volumes Linguistic Studies of Text and Discourse and Halliday in the 21st Century (Chapter 3) and in particular, his articles of "How is a text like a Clause?" [13], "Dimensions of Discourse Analysis: Grammar" [15], "The analysis of scientific texts in English and Chinese" [17], and "On the grammatical foundations of discourse" [20] where he offers us general principles and case studies of SFDA, and where he 'explores the largely interchangeable concepts of text and discourse' [35]. Or more exactly, according to him [24][25: 55], 'discourse' and 'text' are the terms that refer to the same thing with different standpoints:

'Text' is discourse that is being viewed as a linguistic process (hence 'texts' are pieces of language), while 'discourse' is text that is being viewed as a socio-cultural process (so 'discourses' are kinds of language) (and cf. Halliday, 2008: 77-8). This means that 'discourse' is likely to refer to texts of more than minimal length; apart from that, any passage of wording may be referred to in either way.

In addition to Halliday, Hasan [32], Fawcett [5], Martin [63], Martin \& Rose [64], Matthiessen [66], Ravelli \& McMurtrie [69], Bloor \& Bloor [1], Hyland \& Paltridge [56], Hu, Zhu \& Zhang [39], Hu, Zhu, Zhang \& Li [40], Huang [41,43-44,50-52], Huang \& Xu [55], Zhang [73-74], Peng [68], He [34], among many others, have also contributed a lot in one way or another to the development and research of SFDA.

So far, a number of significant studies have been available in the discussion of the past achievements and future possibilites of SFDA. For instance, in Miao's [61] view, SFDA has developed from the 1960s into a transdisciplinary research area in relation to many disciplines. He suggested the new discourses such as those in computer-mediated communication, especially those based on hypertexts, emails, online chats, virtual games will offer new challenges and opportunities to the development of SFDA theoretically and methodologically. In addition, latest developments in cognitive science, especially relevance theory, accessibility theory, text world theory, centering theory, and discursive psychology, are implicitly pushing SFDA ahead. Also, the relation between discourse and society has been one of the main concerns in recent discourse analysis. Critical discourse analysis, institutional discourse analysis, and organizational discourse analysis are significant developments, especially in their application to the analysis of media discourse, and discourse in relation to gender and gender identity, racial discrimination, as well as culture, cross-cultural communication, cheat, misunderstanding, morality, employment, nature and surroundings, globalization, human rights, history, and others. Zhang [73] discussed the development of SFDA in multimodality. Feng, Zhang \& O'Halloran [6] argue that multimodal discourse analysis has become a new discipline with inter-disciplinary frameworks integrating linguistics, media and communication studies, cognitive science, and others. Besides, Huang [45,50], Huang \& Xin [54], Li \& Lu [59], Wu [70], Peng [68], Cheng \& Zhang [2], Geng \& He [9] and many others also approach this topic from alternative perspectives.

\section{Past Achievements of SFDA}

In brief, there are eight principal past achievements of SFDA, which include:

(i) Construal of world famous DA theories that are complete, highly appliable, and SFL theory-rooted. One of the representations is the publication of Halliday's classic work IFG1 [14], which states clearly that it serves the purpose of DA.

(ii) Emergence of the "Golden Delta" of research. This Delta, which covers the whole world, centers around where M. A. K. Halliday grew and developed academically, i.e., Oceania (Australia), Europe (UK) and Asia (China). The map of Halliday's academic growth and development is something like this: from UK to China, back to UK, then from UK to Australia, and later mainly to and fro Australia and Hong Kong. At his early academic years, Hallliday learned from Prof. Li Wang and Prof. Changpei Luo and "zhōng wéi yáng yòng" (made Chinese academics applied to western academics) [71], which lay a solid foundation for the writing of his $\mathrm{PhD}$ thesis. UK is the key place for his systemic-functional linguistic theory. China and UK constitutes the complementarities in regions of the east and west hemispheres, whereas Australia and China brings his thoughts of "SFL as appliable linguistics" into full play.

(iii) Numerous publications in various disciplines. There have been a growing number of research articles and books in relation to SFL and SFDA. Based on an incomplete statistics at http://www.isfla.org/Systemics, there are over 460 books, in addition to Halliday's 206 articles and books. Since 1989, scholars in mainland China have also published over 100 (edited) books. The annual number of world books increases from $0.9(1959-1984)$ to $9.2 \quad(1985-2000)$, and 22.6 
(2001-2018), covering a variety of SFL-appliable fields.

(iv) Development of different analytic models. Along with the advancement of SFL and SFDA, there have emerged a large number of analytic models with various foci. Following Halliday's foundational and comprehensive analytic models of top-level design, his followers throughout the world have offered improved or practical models of different kinds. These include Halliday Model or Sydney Model, Fawcett Model or Cardiff Grammar Model, Martin Model or Discourse Semantic Model and Appraisal Model, Hasan Model or Generic Structure Potential Model, Matthiessen Model or Systemic Model, Hoey Model or Textual Lexis Model, Kress \& van Leeuven Model or Multimodal Discourse Model, among others.

(v) Establishment of many SFDA-related international, regional and national associations, institutions and research centres across Europe, North America, Latin America, Asia, especially in SFL associations in countries such as Australia, China, and France.

(vi) Regular various academic activitiies held by these associations, institutions and research centres. These include establishment of various courses for master degree and $\mathrm{PhD}$, and cultivation of a large number of excellent research talents, which is best true of Australia and China [48].

(vii) Creation of well-known SFDA-related international and national academic journals. These include (international) such systemic-centred journals as Functions of Language, Functional Linguistics, Language, context and text: The social semiotics forum, and such systemic-friendly journals as Linguistics and the Human Sciences, Social Semiotics, Word, Applied Linguistics, Text and Talk, Linguistics in Education, Language Sciences, Journal of Applied Linguistics, English for Specific Purposes, DELTA, and Clinical Linguistics and Phonetics; (in China) Annual Review of Functional Linguistics, Studies in Functional Linguistics and Discourse Analysis, and others.

(viii) Setting up of websites and developmental channels with rich SFDA-related resources (cf. www.isfla.org/Systemics).

\section{Future Possiblities of SFDA}

As appliable linguistics, SFL offers a general guideline for the future direction of development of SFDA with a wide scope of application. We argue the future possibilities of SFDA may include macro-issues, micro-issues, theoretical and practical aspects as follows.

\subsection{Macro Planning}

For a long time, research of SFL and SFDA has covered too many fields with too many directions which split research forces. If this problem cannot be solved, it is hard to integrate SFDA research forces and create something phenomenal. To promote the competitativeness of SFDA in the linguistics circle, it is necessary to deal with the relationship between comprehensive research and top-level design and overall research planning. For instance, throughout the world or in the scope of a particular region, a short-, medium-, and long-term research planning may be made with every stage guiding researchers towards focusing on a/some key research projects, significantly turning SFDA into "appliable DA". This paper holds that because of such issues of theoretical applicability, researchers' various interests, and different degrees of research difficulty in context, there emerges a comparatively serious "inbalance" in SFDA research, which is realized as: more in applicational analyses, less in theoretical analyses; more in functional analyses, less in systemic analyses; more in analyses of written discourse, less in analyses of oral discourse, and so on. Macro planning might be a possible way to sovle this problem.

\subsection{Micro Deepening}

Despite praiseworthy achievements in both theory and application, SFDA still needs micro deepening in its research. For instance, some existing analytic models are too abstract or disagree with the linguistic and cultural facts to be practical and feasible [60], which occasionally results in different statistics and conclusions from the analysis of the same discourse, as is the case of the analysis of Martin Luther King's "I have a dream". In addition, Halliday's theoretical and practical models about systemic functional cognition also need micro deepening.

\subsection{Theoretical Exploration}

From the perspective of Halliday's system of theory, SFDA has a rather perfect integrated framework. But from the perspective of "species", there are still numerous theoretical issues to be sovled within Halliday's system of theory, some of which are related to the problem of deepening and perfection in need, and others of which are related to the problems of integration, development and application. For instance,

\subsubsection{Issue of Definitions of "Discourse/Text", "SFDA", Etc}

According to Halliday \& Hasan [28: 1], "text" is so defined, "The word TEXT is used in linguistics to refer to any passage, spoken or written, of whatever length, that does form a unified whole." This paper argues that from the perspective of semantics, the main clause and the subordinate clause in this definition should be reverse with an addition of the word "semantics", i.e., "The word TEXT is used in linguistics to refer to a unified semantic whole, which can be realized by any passage, spoken or written, of whatever length." Otherwise, the definition may cause confusion to the concepts of abstract and concrete "text". Besides, misunderstandings outside the circle of SFL/SFDA are also related to the ambiguous defintion and analyses. Halliday's [24: 55] distinction discussed above between 'discourse' and 'text' can offer some help to his followers in this aspect. Furthermore, what is the definition of SFDA? So far there is little systematic elaboration of it available. Huang [45] proposed the definition of "functional discourse analysis" (FDA), i.e., FDA refers to "discourse analysis based on Halliday's SFG." Our question is why he did not use SFDA. There are three possible reasons: 
The first is that the analytic framework IFG [14, 18-19, 27] offers does not include the part of "system". The second is that FDA is aimed at the analysis of language functions, but not the analysis of language systems. The third is that the existing DA practice centers normally on language functions, seldom on language systems. As Halliday's theoretical goals of SFL are directed to both "system" and "function", FDA in the terms of the nature of theory and in the broadest sense belongs to SFDA. And SFDA can be taken as having one of these two definitions: one in a broad sense, and one in a narrow sense. In a broad sense, any DA that applies ideas and theories of SFL, no matter how little it uses, can be said to belong to SFDA, or what we may call "Big SFDA". In a narrow sense, only the DA that strictly follows the ideas, theories, methods, techniques, etc., belongs to SFDA, or what we may term "Small SFDA". The division of big and small SFDA is because of (i) different purposes and layers of DA -- In the course of DA, people will normally decide on an analysis in a broad or narrow sense, casually or seriously, simply or in a in-depth manner, according to their different purposes and obtainable analytic layers in different contexts; (ii) instrumentality and evidentiality of DA -- Regularly, the purpose of DA does not lie in the analysis itself but in obtaining useful data or evidence by the analysis; and (iii) ambiguity in the combined uses of different analytic methods in the analysis -- Sometimes a DA may need to include two or more than two analytic methods of "Small SFDA" simultaneously, and their methods are ambiguous in determining which is which in the process of analysis.

\subsubsection{Issue of Discourse/Text Types}

Linguists including Martin [63], Huang [42] Halliday \& Matthiessen [27, or IFG4] have offered significant studies on the issue of discourse/text types. However, so far there has been no definite solution to this issue. A comparatively universal viewpoint is that discourse/text types should be determined by the three variables of register ${ }^{1}$. Martin [62: 309] classified texts into four basic types from the perspective of science and humanities, i.e., (i) science: report: taxonomizing; (ii) science: explanation; (iii) humanities: report: generalizing; (iv) humanities: exposition. Huang \& Ghadessy [53] discussed five types of discourse: newspaper reporting, letters to the editor, self/product promotion discourse, classroom interaction, and the discourse of history. Halliday \& Matthiessen [27: xv, 3, 37] proposed 'a scheme for classifying texts according to contextual variables', he classified texts into two types: text as instrument, and text as an object. In addition, he also classified texts into eight types (expounding, reporting, recreating, sharing, doing, enabling, recommending, and exploring) and seventeen subtypes. But there exist some relevant problems: What is the relationship between this classification and the process types in the transitivity system?

1Matthiessen [233]: Halliday \& Hasan argue that 'genre' is not a theoretical term, synonymous with 'register', and traditionally it is applied in literature research. But Martin argues that 'genre' and 'register' belong to different layers of semiotics, with the former being at the second layer above language whereas the latter being at the first layer.
How do the six process types develop into these eight types of texts? What is the relationship between this classification and Martin's? All such issues need further explorations. The key to and difficulty in the determination of text types lies in where on earth to start in the continuum of discourse/text comprehension of between two ends of context (top) and spelling/phonetics (bottom). Is it that we can start an analysis of discourse from any spot except the realizational layer of spelling/phonetics? Why yes or why not? From the perspective of generalization, the fewer text types the nearer the generaliztion to context, and the more text types the nearer the generaliztion to spelling/phonetics. From the perspective of system network, any sub-network can be taken as the starting point in determining the text types, and any functional component in any system network can be taken as an independent text type.

\subsubsection{Issues of Types, Methods, Approaches, Steps, Layers, Etc., of $S F D A$}

First, the issue of types of SFDA. For instance, probably SFDA can be classified from various perspectives, such as: (i) abstract/concrete: two types, or theory and practice; (ii) completeness of theory: five types, or promotive introduction, criticism, modification, development, variation; (iii) modes of application: three types, or direct adoption, adoption and modification, reconstruction; (iv) fields of application: various types, or teaching, linguistics, literature, translation, etc.; (v) practicality: two types, or life and art; (vi) number of languages: three types, or monolingual, bilingual, and multilingual; (vii) scope of observation: two types, or macro and micro; (viii) types of text/discourse: two types, or spoken and written; (ix) text/discourse carrier: two types, or electronic and non-electronic; (x) status of text/discourse: two types, or process and product; (xi) purpose of analysis: two types, or task and tool; (xii) method of analysis: two types, or quantitative and qualitative; (xiii) characteristics of analysis: two types, or universality and disparity; (xiv) manner of existence: two types, or mental and behaviour; (xv) behaviour: two types, or individual and collective; (xvi) activeness: two types, or active and passive; (xvii) consciousness: two types, or voluntary and non-voluntary; (xviii) tool: three types, or interactional, pedogogical, and research; (xix) time: two types, or synchronic and diachronic; (xx) space: three types, or local, alien, and cross-regional; and so on. In terms of method of analysis, there are three prevailing methods: partial, partial-whole, synthetic. According to IFG4 [27: 480], SFL adopts a synthetic analysis of "three dimensional perspectives" (which includes top down, outside in, and bottom up analyses). However, most practioners adopted a particular SFDA analytic model with one of the first two perspectives, especially the outside in analysis, as in the analysis of a text with the application of ideational metafunction, so as to draw conclusions. The problem is: Why is what Halliday stresses one thing whereas its practice another? Is it because the synthetic analysis of "three dimensional perspectives" too difficult to operate? Or how can this kind of analysis be best done? What are the advantages 
and disadvantages of the above-mentioned types of analysis? What effect do they have on the efficiency and quality of analysis? In addition, there are the problems of analytic approaches. In summary, there are five main analytic approaches: (i) macro and micro; (ii) inward (theoretical studies) and outward (applicational studies); (iii) jump-in (DA with the application of SFL theory) and jump-out (DA by jumping out of the SFL theoretical framework and taking a view of it); (iv) opting for a/some sub-theories for a quantitative and/or qualitative analysis of functional items of a specific discourse with an occasional analysis of system network; (v) quantitative and qualitative. Besides, there is the problems of analytic steps. As early as the 1980s, Halliday [15, 22: 197-227] proposed a ten-step SFDA, but occasionally discarding the analysis of "intonation and rhythm" and "logical-semantic relation". Huang [45] also held the view that SFDA can take the route of top ("context of culture") down ("language use") and bottom up. This kind of analysis has an advantage of making the the person who analyzes the discourse fully aware of the requirements of each step, and a disadvantage of including too many steps or too many details to remember. Therefore, Halliday [19, or IFG2: F41] proposed a two-layered DA. Based on this, Huang [45] proposed a five-step DA and a six-step DA, clearly a development of Halliday's DA. This paper argues that a seven-step DA may be proposed based on Huang's six-step DA by adding "application". That is because SFDA may focus too much of discourse itself, but it may also be applied to things outside discourse. When the latter situation occurs, SFDA may serve as a tool for the key to questions outside a/some discourse, which means the first six steps are also needed in application outside the discourse, as their application results are used to prove a certain argument, and hence the application will directly affect the starting points and specific operations of the first six steps. Thus, the addition of the seventh step is particularly necessary in Big SFDA. What is more, qualitative studies can be further deepened, and research on the assessment of characteristics, meaning and value of data in quantitative analyses as well as the development of relevant applicational softwares can also be deepened. Then the issue of layers of analysis. This paper holds that Halliday's "two-layered DA" is oversimplified, so much so that although there have been available rich achievements of SFDA and discourse appraisals, which is particularly true of the former, frequently we encounter the situations where with all the analysis, it is hard to how to go on saying accurately and how to draw safe conclusions. Despite the fact that Halliday, Martin, and many others have provided us with many analytic cases, we still find it somewhat difficult in the process of application to understand and appraise discourse in depth and in scientific manner. Besides, maybe SFDA can be categorized from other perspectives. For instance, it can be categorized from the perspective of "jumping outside discourse/text" into these four main layers: (i) social analysis: SFDA for the existence of human beings without any practical guidance of SFL; (ii) learning analysis: DA operations for the mastery of the tool of SFDA; (iii) language analysis: DA for the characteristics of systems and functions of language through the analysis, exposition and assessment of the language of the analyzed discourse; (iv) instrumental analysis: use of DA as an instrument to solve the problem of the researchers. All this still needs further exploration.

\subsubsection{Issues of the History, Object/Subject, Position, Etc., of SFDA}

These are issues that are seldom studied. In terms of the history of SFDA, according to Halliday [19: F39], the language system today is the result of evolution of language over tens of thousands of years based on the continual satisfaction of social and human needs. Therefore, probably the practice of SFDA began ever since the emergence of human language, and it has been going on and on; it is the realization of an actual fact of human communication, and a must price to pay for the success of human communication. And in the slow process of language development, SFDA had merely existed in people's mind as an abstract social behaviour and had not formed a specific theory until the foundation of SFL by Halliday who truly established a theory of SFDA. It may be said, therefore, that the history of SFDA is actually the history of language development in a broad sense, and the history of SFL in a narrow sense. In terms of object/subject of SFDA, the subjects of SFDA can be roughly classified into three groups: (i) anyone in social life, who is supposed to be doing SFDA daily with or without the guidance of theory; (ii) teacher and students in (especially language) teaching, who learn and master the basic theory and methods through teaching and practice of SFDA; (iii) researchers of SFDA, who promote the progress of theory and practice of SFDA. What is the key of the key issues in the future construction of SFL as appliable linguistics may be how the theory of SFDA can be promoted among the first group of subjects. The objects of SFDA, on the other hand, can be any discourse/text, spoken or written. The existing achievements especially those in China mainly focus on written discourse/text, and theoretical and applicational explorations of spoken discourse/text are still in great need, particularly in the combination of SFDA and corpus research. In terms of the position of SFDA, what is the position of SFDA in SFL? This paper holds that the answer to this question may signficantly inflence the future direction of SFL, and therefore it needs some exploration. The present paper argues that from the perspective of the structure of the theorectical system of SFL, SFDA can be positioned as a sub-system of (lexico)grammar of SFL, subordinate to SFL. But from the perspective of function and role, SFDA is positioned as the core of SFL, which is realized in what follows: (i) Halliday [19: F41] clearly stated that his SFG is constructed for the purpose of DA; (ii) to date, almost all SFL studies have been based on DA; (iii) Halliday $[21,23]$ put forward the slogan of establishing an appliable linguistics, in which he specified his thoughts that SFL is appliable linguistics. But the problem is: What is the time span for the construction of SFL as an appliable linguistics? Or: Is "SFL as an appliable linguistics" everything of SFL? 


\subsubsection{Issues of Comprehension and Integration of Various Theorectical Models}

As mentioned above, SFDA has various theoretical models, and there exist significant differences between these models. This is disadvantageous to the choice of models for analysis, and sometimes easily misleads people to think of the imperfection of the existing models. What are the relations between these various models? Can they be integrated into a better model of DA? Over the many years, Martin Model and Fawcett Model have continuously been developed, but Halliday Model does not seem to include them as part of itself. Why is that? Is it because these three models are the results of different perspective and they can co-existent without contradictory to each other? Or is it because Halliday regards his own model as complete, and Martin Model and Fawcett Model are just alternatives or variations, and despite differences, they are the same theoretically, and they are simply the enrichment and development of SFL? Or since Halliday has long stressed the natural state, harmonious complementarity and multi-development in research of SFL and SFDA [29], does it mean various models of SFDA like every live individual in our biological environment have their own system and life, originating from the same species without the possibility of integrating all of them one and only one whole? This paper tends to lend support to the last idea. But, still, this indicates the basic theory of SFDA, or SFG/SFL remains to be further perfected in the future [73,77-78]. In addition, the literature to date shows that SFDA is very strong in functional analysis, but very weak in systemic analysis, though the latter is rather matured. Also there are many other problems to be solved. For instance, what is the complete system network of language? What is the relation between all its sub-systems? As occasionally, there exist conflicts, counteraction, integration, rejection, deletion, weakening, assimilation, etc., among sytem and sytem, and function and function, how should these contents be analyzed? Thirdly, we agree with Huang [48], Hu [38], and others in their discussion of the theoretical construction of SFDA. Meanwhile, we want to add a number of questions as follows: In terms of multimodal DA, how can discourse and images, pictures, audios, videos, etc., be better integrated in the analysis based on the existing analytic models? How can variables be controlled? How can reliability and validity of analysis be further improved? How can the issue of too many variables be sovled? What is the transformation between different media of discourse/text? Can there be a theory of such a transformation? In terms of the comparative analysis of English and Chinese discourse/text, what is the theory and system of such an analysis? What are the bases, criteria and principles of the comparative analysis of English and Chinese discourse/text? In terms of the integration of DA and translation studies, are the existing DA in translation studies systemized and theorized? Do they need further deepening? Or is it likely to propose a theory of translational SFDA for the guidance of translation practice? In terms of critical DA, is it likely to further the theoretical research on the critical width, depth and validity of critical DA? In terms of the integration of DA and corpus linguistics, how can they be better integrated, so as to contrue a systematic science of corpus DA? In terms of the integration of DA and foreign language teaching, though Zhang [73] and others have made great contributions to this aspect, it is something that has a very big potential space of further research.

\subsubsection{Issues of Theoretical Application and Originality}

Issues of theoretical application and originality involve what follows: (i) In terms of monolingual SFDA, comparatively less in-depth English analysis in research of phonology, morphology, language change, second language acquisition, diachronic linguistics, discourse/text evolution, comparison between modern/contemporary and ancient discourse/text, paradigmatic patterning, quantitative and qualitative analysis of the same discourse/text type, the evolution of the same discourse/text type [16]. Besides, as no satisfactory conclusions can be drawn by the direct application of the existing analytic models in the analysis of Chinese discourse/text [26, 75-76], what is in urgent need is the construction of a theoretical framework of SFDA for the Chinese language, i.e., the construction of various functional systems and subsystems that are fit for the Chinese facts. (ii) In terms of bilingual or multilingual SFDA, as English and the other world languages have different linguistic systems and cultural contexts, are the analytic models such as Halliday's that are suitable for the English language also suitable for the other world languages? What is the comparibility of the construction of the bilingual or multilingual SFDA models? What is their reliability and validity? All this needs our further consideration. (iii) In terms of translational SFDA, Huang [46] and others have made great contributions to the integration of SFDA and translation studies in China. Generally speaking, the existing translational SFDA is successful in that it helps solve some problems in the practice of translation. But because translation is a very complex process, translational SFDA research still has much room to improve. Translation involves many factors such as the systems, individuals, time, space, etc., of two discourses/texts [10,66], how many factors are realized in the existing practice of translational SFDA? To what extent are they realized? How are they equivalently transformed? What are the principles of the transformation? and so on.

\subsection{Practical Standardization}

There are different kinds of inconsistency or disagreement in the practice of SFDA, which needs standardization. What follows are some cases of term inconsistency.

\subsection{1. "Discourse/Text"}

Halliday [29], $\mathrm{Hu}$ [36: 2], Huang [49], and others have realized the issue of the term "discourse/text" in SFDA. "Discourse", "text", "yŭpiān", "wénběn", "piānzhāng", "huàyŭ", etc., are co-existent in academic studies and practice. In IFG4 [27], the terms "text" and "discourse" are used 1638 and 172 times respectively in the body of the book, and they 
are used 28 and 72 times respectively in References of the book. Although Halliday [24: 55, 29] thinks that, as mentioned above, "text" and "discourse" are the same phenomenon viewed from different perspectives, and "text" is used from the perspective of linguistic unit itself, whereas "discourse" is used from the perspective of outside linguistic unit, which is supported by Harris's [30-31] early paper topics and Leech's [57: 59] viewpoints, the application still seems to be problematic. Huang [49] holds that the use of the terms should be dependent on who is using them and what questions they are discussing. This paper holds that (i) in agreement with Halliday [24: 55], "discourse" and "text" are two different standpoints of the same phenomenon; (ii) both of them can be spoken and written; (iii) there are differences between them; (iv) their major difference lies in their different standpoints; (v) semantically, "discourse" is superordinate to "text"; (vi) the theoretical exploration of their differences can go microscopically to a particular genre, and macroscopically to the general framework of semiotics. Besides, in their Chinese translations, this paper agrees with Zhu's translations [75], i.e., to translate "discourse" and "text" into "huàyü" and "yüpiān" respectively. That is because despite the fact that both can be spoken or written, spoken language relies more on context and with richer meanings, and because the translation of "text" into "yüpiān" has long taken a better root in the circle of SFL/SFDA.

\subsection{2. "Discourse/Text Analysis"}

Should we use "discourse analysis" or "text analysis" or others? This sometimes causes trouble to the circle of SFL/SFDA. On December 7, 2018, we input the following search phrases "discourse analysis", "text analysis", "critical discourse analysis", and "critical text analysis" into the topic frame of CNKI journals (www.cnki.net) respectively, and we got these results (articles): "discourse analysis" 6916, "text analysis" 7569, "critical discourse analysis" 1372, and "critical text analysis"15. And with the use of the same search strategy, we obtained from the titles of CNKI key journals the result of "yüpiān fēnx $\vec{\imath} "$ (DA) 211, of which that have translations, "yüpiān fēnx $\vec{\imath} "$ is translated into English of "discourse analysis" 61, "text analysis" 5, "analysis of ... text" 5, "textual analysis" 4, "discourse/text analysis" 1, "discourse approach" 1, "discoursal" 1, "discourse(-historical) analysis" 1 , "discourse analytical (approaches)" 1, "textual analysis" \& "discourse analysis" 1, "discourse (approach)" 1. In addition, the translation "textual analysis" is mainly used by scholars outside the circle of SFL/SFDA. And "discourse studies" is a term Huang [47] proposed as a solution to the issue of inconsistency in the term use of "discourse/text analysis". "Discourse analysis" as used at the earlies stage by Harris [30] refers to an analysis of relevant oral or written language. But because IFG1 [14] stresses its purpose is to serve "text analysis", and IFG4 [27] uses "text analysis" 6 times in the body of the book and 2 times in References, "discourse analysis" 1 times in the body of the book and 9 times in References, and IFG1 [14] uses "text analysis" 3 times in the body of the book, without illustrating their differences, then our questions are as follows: What are their differences in SFDA? What is the difference between "text analysis" in SFDA and Harris's [30] "discourse analysis"?

\subsection{3. "Systemic-Functional Discourse/Text Analysis"}

Which should we use, "Systemic-Functional Text Analysis" (SYSFUNTA) or "Systemic-Functional Discourse Analysis" (SYSFUNDA)? The answer to this question also relies on the understanding of "text (analysis)" and "discourse (analysis)". If "text" and "discourse" are interpreted as "yüpiān" and "huàyŭ" respectively, then we had better use SYSFUNTA for "xìtŏng gōngnéng yŭpiān fēnx $\vec{\imath}$ ", and SYSFUNDA for "xìtŏng gōngnéng huàyŭ fênx $\vec{\imath}$ ". Therefore, we suggest this is best practiced and kept in Chinese context. The literature shows that the term "Systemic-Functional Discourse/Text Analysis" is normally realized in English research and practice as without the words of "systemic" or "functional" and "text" or "discourse" [3: 309], and "Systemic Discourse Analysis" is seldom used. What is noteworthy, however, is that there are often no actual big differences in their analyses. This paper argues that in order to avoid the confusion, it is necessary to investigate the usages of SFL/SFG/SFDA terms in both theory and practice and find a solution to the standardization of the use of the terms concerned.

\subsubsection{Other Terms}

There are also inconsistencies in other terms. For instance, there is an inconsistency in the Chinese translation of the term "attributive": "guīshŭshi" [72], "guīshü" [40: 79], "guīshŭlèi" [76], "xiūshixing" [43], etc. This may be due to these factors: (i) There are occasional inconsistencies in Halliday's own terms. Take "metafunction" for instance. What follows are its actual usages in IFG4 [27]: ideational function (2 times), ideational metafunction (14 times), interpersonal function (3 times), interpersonal metafunction (9 times), textual function (4 times), textual metafunction (14 times), experiential function (8 times), experiential metafunction (4 times), logical function (0 times), logical metafunction (4 times). (ii) Affected by traditional terms, different scholars preferred their habitual terms in Chinese. (iii) Because the English term has at least somewhat different features and connotations in respect of SFL, SFG and SFDA, different scholars applied what they thought most suitable terms in Chinese. (iv) The result of omission. Just as "ideational metafunction" can be simplified as "ideational function", the Chinese terms "yuán gōngnéng" and "chúnlì gōngnéng" are often simplified as "gōngnéng". Hence it is advisable that regional or international associations of SFL organize researchers to look into such issues, or fund relevant projects so that people are guided by the standardization of the usages of terms which will help our readers out of the trouble of these inconsistencies.

\subsection{Popularization and Promotion}

As it seems, SFDA, including their research and practice, is better done primarily in Australia, UK, and China, and further efforts are needed in the other countries and regions. This paper holds that even in China, SFDA also has a great 
potential. For instance, the coursebook of linguistics by $\mathrm{Hu}$ [37], compiled based on SFL, can actively promote the cultivation of college students' competence in SFDA. But probably for the consideration of the students' need for comprehensive linguistic knowledge, this coursebook is not totally organized from the perspective of SFL. The book $A n$ Introduction to Systemic-Functional Linguistics by $\mathrm{Hu}$ et al. [40] is a milestone coursebook in the circle of Chinese SFL. But is it too theoretical and too lengthy for an outsider without any basis and knowledge of SFL? And is it possible, based on the present book, to simplify its theoretical contents, so as to highlight the practicality of DA, and to offer a popular edition of the book with a focus on case studies?

\section{Concluding Remarks}

This paper offers a rather general discussion of the past achievements and future possibilities of SFDA, which leads us to the tentative conclusion that there is still a lot of room for the research on SFDA. The strengths of this paper include: (i) a retrospective and prospective discussion of SFDA based on the actual practices in China and other countries; (ii) a multiperspective approach including both macroperspective and microperspective analyses are adopted in the discussion; (iii) problems and debates in SFDA are presented and shortly discussed; (iv) novice ideas and challenges are suggested for future studies in SFDA. And the obvious weaknesses of the present paper include: (i) the discussion is done in a comparatively narrow sense. In a broad sense, everything available based on SFL theory may be taken as the fruit of SFDA, and hence there would be quite different outcomes of the discussion with the same topic; (ii) most issues are simply touched upon without in-depth exploration, which might hinder the complete understanding of the relevant concepts; (iii) all the discussion is done mainly from the view of the author as a Chinese scholar who sudies SFDA, which might lose the whole picture of SFDA in some sense; (iv) no clear methodology and theoretical framework is given, which results in less tidy and coherent organization; (v) no truly quantitative analysis of SFDA literature is done, which makes the conclusion of this paper tentative and less convincing. All this may be taken as the future work direction of the author of this paper and perhaps also that of people who intend to do similar research work.

\section{References}

[1] Bloor, T., \& Bloor, M. (2013). The Functional Analysis of English (3rd ed.). London: Routledge.

[2] Cheng, R. L. \& Zhang, D. L. (2017). Multimodal Discourse Analysis in China: Taking Journal Articles as an Example. Foreign Languages in China, 3, 36-44.

[3] Eggins, S. (1994). An Introduction to Systemic Functional Linguistics. London and New York: Continuum.

[4] Fawcett, R. (2008). Invitation to Systemic Functional Linguistics through the Cardiff Grammar: an extension and simplification of Halliday's Systemic Functional Grammar. London: Equinox.

[5] Fawcett, R. (2010). A Theory of Syntax for Systemic Functional Linguistics (Current Issues in Linguistic Theory 206). Amsterdam: Benjamins.

[6] Feng, D. Z., Zhang, D. L., \& O'Halloran, K. (2014). Advances and frontiers of multimodal discourse analysis. Contemporary Linguistics, 16 (1), 88-99 + 126.

[7] Fryer, D. L. (2012). Analysis of the generic discourse features of the English-language medical research article: A systemic-functional approach. Functions of Language, 19 (1), $5-37$.

[8] García, M. P. A., Sagre, B. A. M., \& Lacharme, O. A. I. (2014). Systemic Functional Linguistics and Discourse Analysis as Alternatives When Dealing with Texts. Profile: Issues in Teachers' Professional Development, 16 (2), 101-116.

[9] Geng, F., \& He, W. (2018). The Integration, Innovation and Development of Functional Linguistics: Review of the First High-end Forum on the Integration and Development of Functional Linguistics and Commemorative Symposium for Prof. M. A. K. Halliday. Journal of University of Science and Technology Beijing (Social Sciences Edition), 4, 1-8.

[10] Gu, Z. K. (1990). Five approaches to the appreciation of world poetry. In Z. K. Gu (ed.), A Guide to Appreciation of Masterpieces in World Poetry (pp. 1-14). Guilin: Lijiang Publishing Limited.

[11] Halliday, M. A. K. (1955). The Language of the Chinese Secret History of the Mongols. Ph.D. Thesis submitted to Cambridge University. Published as: Halliday, M. A. K. (1959). The Language of the Chinese Secret History of the Mongols. Oxford: Basil Blackwell. Publications of the Philological Society XVII. The appendix "Phonological (prosodic) analysis of the new Chinese syllable (modern Pekingese)" was reprinted in Frank Palmer (ed.). (1970). Prosodic Analysis. London: Oxford University Press.

[12] Halliday, M. A. K. (1978). Language as Social Semiotic: The Social Interpretation of Language and Meaning. London: Arnold.

[13] Halliday, M. A. K. (1982). How is a text like a Clause?. Stu Allen (ed.). Text Processing: Text Analysis and Generation, Text Typology and Attribution. (Proceedings of Nobel Nobel Synposium 51, pp. 209-247). Stockholm: Almqvist \& Wiksell International. Reprinted (combined with "Text semantics and clause grammar") in Halliday, M. A. K. \& Jonathan Webster. (2002). On Grammar. Collected Works of M. A. K. Halliday, vol. 1. Edited by Jonathan Webster. Continuum.

[14] Halliday, M. A. K. (1985a). An Introduction to Functional Grammar. London: Arnold.

[15] Halliday, M. A. K. (1985b). Dimensions of discourse analysis: grammar. In M. A. K. Halliday (2007), On Grammar (J. Webster ed.) (pp. 261-186). Beijing: Peking University Press.

[16] Halliday, M. A. K. (1990). New ways of meaning: a challenge to applied linguistics. Journal of Applied Linguistics, 6, 7-36.

[17] Halliday, M. A. K. (1992). The analysis of scientific texts in English and Chinese. In M. A. K. Halliday, \& J. R. Martin (eds.), Writing Science: literacy and discursive power (pp.124-132). London \& Washington, D. C.: Falmer Press.

[18] Halliday, M. A. K. (1994). An Introduction to Functional Grammar (2nd ed.). London: Arnold. 
[19] Halliday, M. A. K. (1994/2000). An Introduction to Functional Grammar (2nd ed.). London/Beijing: Arnold/ Foreign Language Teaching and Research Press.

[20] Halliday, M. A. K. (2001). On the grammatical foundations of discourse. Ren Shaozeng, William Guthrie and I.W. Ronald Fong (eds.) Grammar and Discourse: proceedings of the International Conference on Discourse Analysis (pp.47-58). Macau: University of Macau Publications Centre.

[21] Halliday, M. A. K. (2006). Some theoretical considerations underlying the teaching of English in China. Journal of English Studies, 4: 7-20.

[22] Halliday, M. A. K. (2007). Linguistic Studies of Text and Discourse (J. Webster ed.). Beijing: Peking University Press.

[23] Halliday, M. A. K. (2008). Working with meaning: towards an appliable linguistics. In J. Webster (ed), Meaning in Context: Implementing Intelligent Applications of Language Studies (pp. 7-23). London: Continuum.

[24] Halliday, M. A. K. (2011). Text, Discourse and Information: A Systemic-functional Overview. Journal of Peking University (Philosophy and Social Sciences), 1, 137-146.

[25] Halliday, M. A. K. (2013). Halliday in the 21st Century. Collected Works of M. A. K. Halliday, vol. 11. Edited by J. Webster. London: Bloomsbury.

[26] Halliday, M. A. K. (2014). That "certain cut": towards a characterology of Mandarin Chinese. Functional Linguistics, 1 (2), 4-23.

[27] Halliday, M. A. K. \& C. M. I. M. Matthiessen. (2014). An Introduction to Functional Grammar (4th ed.). London: Routledge.

[28] Halliday, M. A. K., \& Hasan, R. (1976). Cohesion in English. London: Longman.

[29] Halliday, M. A. K., Hu, Z. L., \& Zhu, Y. S. (2010). Interviewing Professor M. A. K. Halliday by Hu Zhuanglin and Zhu Yongsheng. Foreign Languages in China, 6, 17-24.

[30] Harris, Z. S. (1952a). Discourse analysis. Language, 28 (1), $1-30$.

[31] Harris, Z. S. (1952b). Discourse analysis: a sample text. Language, 28 (4), 474-494.

[32] Hasan, R. (2016). Context in the System and Process of Language (The Collected Works of Ruqaiya Hasan, Volume 4) (J. Webster ed.). London: Equinox.

[33] He, H. X. (2015). Research of Systemic-Functional Discourse/Text Analysis (SFDA): Historical Contributions and Future Orientations. Foreign Language and Literature Research, 1 (4): 5-14.

[34] He, H. X. (2018). The discourse flexibility of Zhao Yuanren [Yuen Ren Chao]'s homophonic text. Journal of Chinese Linguistics, 1, 149-176.

[35] Hita, J. A. (2016). Halliday in the 21st Century (Collected Works of M. A. K. Halliday 11). J. Webster (ed). 2013. London: Bloomsbury, viii + 271 pp. World Englishes, 35 (3), 478-480.

[36] Hu, Z. L. (1994). Discourse Cohesion and Coherence. Shanghai: Shanghai Foreign Language Education Press.

[37] Hu, Z. L. (2011). Linguistics: A Coursebook (4th ed.). Beijing:
Peking University Press.

[38] Hu, Z. L. (2013). Research on transdisciplinarity of systemicists. Foreign Languages and Their Teaching, 3, 1-5.

[39] Hu, Z. L., Zhu, Y. S., \& Zhang, D. L. (1989). A Survey of Systemic-Functional Grammar. Changsha: Hunan Education Press.

[40] Hu, Z. L., Zhu, Y. S., Zhang, D. L., \& Li, Z. Z. (2008). An Introduction to Systemic-Functional Linguistics(2nd ed.). Beijing: Peking University Press.

[41] Huang, G. W. (1988). Essentials of Text Analysis. Changsha: Hunan Education Press.

[42] Huang, G. W. (1998). Studies of discourse types in discourse analysis. Foreign Languages Research, 2, 5-8.

[43] Huang, G. W. (2001a). Theory and Practice of Discourse Analysis: A Study in Advertising Discourse. Shanghai: Shanghai Foreign Language Education Press.

[44] Huang, G. W. (2001b). Issues of functional discourse analysis. Foreign Languages and Their Teaching, 12, 1-4, 19.

[45] Huang, G. W. (2002). Aspects of functional discourse analysis. Foreign Language Learning Theory and Practice, 4, 25-32.

[46] Huang, G. W. (2006). Linguistic Explorations in Translation Studies. Shanghai: Shanghai Foreign Language Education Press.

[47] Huang, G. W. (2007). Studies of discourse analysis in China. Foreign Language Education, 5, 6-9.

[48] Huang, G. W. (2009). Systemic-functional linguistics studies in China: Advances and prospects. In Z. X. Zhuang (ed.), Foreign Language Development Strategy Forum in China (pp. 857-892). Shanghai: Shanghai Foreign Language Education Press.

[49] Huang, G. W. (2010a). A Personal Interpretation of the Interview Between Halliday and $\mathrm{Hu} \&$ Zhu. Foreign Languages in China, 6, 25-30.

[50] Huang, G. W. (2010b). Discourse analysis and the construction of systemic-functional linguistic theory. Foreign Languages and Their Teaching, 5, 1-4.

[51] Huang, G. W. (2017). One assumption and three principles for ecological analysis of discourse and behavior. Foreign Language Teaching and Research, 6, 880-889, 960.

[52] Huang, G. W. (2018). From Eco-critical Discourse Analysis to Harmonious Discourse Analysis. Foreign Languages in China, 4, 39-46.

[53] Huang, G. W., \& Ghadessy, M. (2006). Functional Discourse Analysis. Shanghai: Shanghai Foreign Language Education Press.

[54] Huang, G. W., \& Xin, Z. Y. (Eds.). (2012). Developments of Systemic Functional Linguistics. Beijing: Foreign Language Teaching and Research Press.

[55] Huang, G. W., \& Xu, J. (2006). Text analyais and discourse analysis. Foreign Languages and Their Teaching, 10, 1-6.

[56] Hyland, K., \& Paltridge, B. (2013). The Bloomsbury Companion to Discourse Analysis. London: Bloomsbury. 
[57] Leech, G. N. (1983). Principles of Pragmatics. London and New York: Longman.

[58] Li, Z. Z., \& Cheng, Z. H. (2008). Review of Collected Works of M. A. K. Halliday. Foreign Languages Research, 4, 102-104.

[59] Li, Z. Z., \& Lu, D. Y. (2012). Hot Spots and Trends of Systemic Functional Linguistics Research -- A Review of the 12th Chinese Functional Linguistics Conference. Foreign Languages in China, 6, 91-95.

[60] Liu, S. S., \& Liu, L. H. (2012). The Appraisal Approach and Discourse Analysis. Journal of Tsinghua University(Philosophy and Social Sciences), 2, 134-141+160.

[61] Miao, X. W. (2006). Advances and frontiers of discourse analysis. Foreign Language Research, 1, 44-49.

[62] Martin, J. R. (1991). Nominalization in science and humanities: Distilling knowledge and scaffolding text. In E. Ventola (ed.), Functional and Systemic Linguistics: Approaches and Uses (pp. 307-337). Berlin and New York: Mouton de Gruyter.

[63] Martin, J. R. (1992). English Text: System and Structure. Philadelphia/Amsterdam: Benjamins.

[64] Martin, J. R., \& Rose, D. (2007). Working with Discourse: Meaning Beyond the Clause (2nd ed.) (Open Linguistics Series). London: Continuum.

[65] Martin, J. R., \& White, P. R. R. (2005). The Language of Evaluation. Appraisal in English. Basingstoke: Palgrave/MacMillan.

[66] Matthiessen, C. M. I. M. (1993). A unified theory of register analysis. In M. Ghadessy (ed.), Register Analysis: Theory and Practice (pp. 221-292). London and New York: Pinter.

[67] Matthiessen, C. M. I. M. (1996). Lexicogrammatical Cartography: English Systems. Tokyo: International Language Sciences Publishers.
[68] Peng, X. W. (2017). Theoretical and developmental trends of Systemic-Functional Linguistics. Foreign Languages in China, $1,1+10-14$.

[69] Ravelli, L. J., \& McMurtrie, R. J. (2016). Multimodality in the Built Environment: Spatial Discourse Analysis. London: Routledge.

[70] Wu, L. L. (2014). Present research status and developmental trends of Systemic Functional Linguistics. Ability and Wisdom, 8,159 .

[71] Yan, S. Q. (2012). On the theoretical origin and mechanism of the evolutionary theory of meaning. Foreign Language Teaching and Research, 1, 45-53, 158.

[72] Zhang, D. L. (2005). Functions and Styles of Language. Beijing: Higher Education Press.

[73] Zhang, D. L. (2012). New Developments in the Theory of Discourse Analysis and Its Application. Beijing: Foreign Language Teaching and Research Press.

[74] Zhang, D. L. (2018). Investigating the 60 years' development of systemic functional linguistics. Foreign Language Teaching and Research, 1, 37-48, 160.

[75] Zhu, Y. S. (2007). Introduction. In M. A. K. Halliday, Linguistic Studies of Text and Discourse (J. Webster ed.) (pp. ix-xii). Beijing: Peking University Press.

[76] Zhu, Y. S. (2013). Relational Clauses in Classical Chinese from the Perspective of SFL. Journal of University of Shanghai for Science and Technology, 2, 117-121.

[77] Zhu, Y. S., \& Yan, S. Q. (2001). Reflections on Systemic-Functional Linguistics. Shanghai: Shanghai Foreign Language Education Press.

[78] Zhu, Y. S., \& Yan, S. Q. (2011). New Reflections on Systemic-Functional Linguistics. Shanghai: Shanghai Foreign Language Education Press. 